\title{
Reasons and Motivations for Procrastinating Academic Activities in First-Year Medical Students
}

\author{
María Martina Jurado*, Ileana Petra, Norma Yepez, Mariana Fouilloux, Beatriz Zamora \\ Psychiatry and Mental Health Department, Faculty of Medicine, National Autonomous University of Mexico, Mexico City, Mexico
}

Email address:

idamar007@gmail.com (M. M. Jurado), ileanapetra@yahoo.com (I. Petra), normayepez@yahoo.com.mx (N. Yepez), mar_fou@hotmail.com (M. Fouilloux), beatriz.zamora98@gmail.com (B. Zamora)

*Corresponding author

\section{To cite this article:}

María Martina Jurado, Ileana Petra, Norma Yepez, Mariana Fouilloux, Beatriz Zamora. Reasons and Motivations for Procrastinating Academic Activities in First-Year Medical Students. American Journal of Applied Psychology. Vol. 10, No. 3, 2021, pp. 82-88. doi: 10.11648/j.ajap.20211003.14

Received: May 31, 2021; Accepted: June 15, 2021; Published: June 21, 2021

\begin{abstract}
The purpose of this research was to investigate the extent to which procrastination occurs in first-year medical students and the reasons for this behavior. It was a cross-sectional study conducted with 388 medical students from a public university in Mexico City. The Procrastination Assessment Scale-Students (PASS) was used. A descriptive analysis of procrastination behaviors and the reasons for their manifestation was carried out using frequencies and percentages. On the other hand, a comparative analysis was performed using the Mann-Whitney $U$ test for sex, age, and school of origin. In addition, Kruskal-Wallis and Bonferroni tests were performed for high school grade point average, mother's education, and the people with whom the students lived when applying the instrument. About $30 \%$ of the students reported postponing homework or studying, while $27 \%$ or less postpone other activities (e.g., tutoring or academic paperwork). As for the reasons why students delay their chores, the ones that stand out are: poor time management, feeling overwhelmed, laziness, frustration (because they think the task takes too much time), anxiety about the evaluation, perfectionism, and difficulty in making decisions when performing the task. As a result of the comparative analysis, it was found that younger people tend to procrastinate less than older people $(\mathrm{Z}=-2.42 ; \mathrm{p}=.016)$ when postponing their homework. Males tend to do it more than females as a way of experiencing excitement when rebelling against control $(Z=-2.76 ; p=.006)$ and taking risks $(Z=-2.32$; $\mathrm{p}=.020$ ). However, female students tend to procrastinate more than males when they felt overwhelmed by academic work and the lack of time to carry it out $(\mathrm{Z}=-2.47 ; \mathrm{p}=.013)$. In addition, those who attended private schools during high school tend to procrastinate more than those who attended public academies when they have doubts and require assistance but find it difficult to ask the teacher or other people $(\mathrm{Z}=-2.33 ; \mathrm{p}=.020)$. In conclusion, the results of this work will help to know the motivation for postponing academic activities and the influences associated with delaying these responsibilities, and therefore, to develop proposals on dealing with bad practices.
\end{abstract}

Keywords: Procrastination, Academic Procrastination, Medical Students

\section{Introduction}

During higher education, it is frequently to see students having difficulties turning in their work on time, preparing for their exams, and accomplishing all their academic requirements. Some of them study and work, while others live far away from their university campus, others must do household chores or take care of a family member, and so on. However, most students who do not have those responsibilities postpone their homework and school obligations by spending time with other activities such as video games, social networks, or other distractions.

In the case of new students, they must face the transition from high school to college, which includes adapting to new classmates and teachers and developing new strategies to learn information for some subjects, which requires better abilities to adjust. As time progresses and school assignments increase, some students feel overwhelmed by academic requirements, making procrastination appear or accentuate. This situation comes with the adolescent stage where they are 
going through and whose characteristics may reinforce negative and oppositional attitudes.

There are inherent demands to med schools, such as subjects with too much information that they must learn, endof-term exams and additional evaluations in each of them, restricted time to assimilate a large volume of concepts, etc. These situations are often aggravated by the lack of study strategies, poor time management, or lack of vocation for a career with these characteristics. All these aspects will negatively influence their school performance, affecting their level of efficiency and motivation. Therefore, it is needed to investigate how often students, especially first-year students, procrastinate and why they do so since they are transitioning from one educational level to another. The results of this study will allow finding intervention strategies aimed at decreasing procrastination and avoiding its effects on academic and personal life.

Recently it is common to find research on the disturbance of academic conditions in higher education in addition to a great variety of problems, perspectives of analysis, and ways of interpretation. The study of procrastination (which refers to voluntarily postponing activities despite knowing the possible negative consequences of such delay [1], has been approached from various theoretical models; the most important are: 1) Psychodynamic, which explains procrastination as the fear of not accomplishing goals and therefore abandoning tasks, despite having the ability to achieve success; 2) Motivational, referring to the choice between two situations: the hope of reaching success (motivational achievement) or the fear of failure (avoiding a situation perceived as unfavorable), where procrastinators are unmotivated and unsatisfied with the objectives they intend to reach; 3) Behavioral, which states that a behavior is preserved when it is repetitive and remains for its rewarding effects This model considers that procrastinators are those who usually postpone a task that needs more time and looks for quick activities that have positive short-term consequences [2, 3].

Another theoretical model that approaches procrastination is the Cognitive model. It has served as the basis for this research considering that procrastination implicates dysfunctional information processing that involves maladaptive schemas in thinking, which leads to a feeling of inability and fear of social rejection when performing a task. From this perspective, procrastinators experience obsessive thoughts when they cannot accomplish an activity or when the time is running out to complete a task. Frequently, ideas associated with the inability to plan or execute the assignments appear, so they have difficulty estimating and organizing their time. Procrastinators present inadequate reasoning, reaching erroneous conclusions that alter their emotional state, which affects their behavior and causes them to react in a counterproductive manner, generating feelings of inadequacy, low tolerance to frustration, or abandoning important academic activities [2].

Among the studies carried out to investigate procrastination in university students, some have focused on the frequency with which it occurs. For example, in Peru, it has been observed in health sciences, social sciences [4], and business, as well as engineering and architecture [5], that a quarter of students or more tend to postpone the execution of various academic activities. They also pointed out that if procrastination becomes a habit, it affects not only academics but also personal, work, social, and family life.

Other research has looked for factors associated with academic procrastination. It was observed that in the United States, educational psychology students who tend to think that procrastination can have positive benefits (for example, ideas such as "Procrastination allows creativity to occur more naturally"), presented this behavior more frequently [6]. On the other hand, in a study in Spain, psychology students who can adequately interact with others, have a positive mood, and a high emotional quotient (calculated from the combination of four dimensions: intrapersonal, interpersonal, stress management, and adaptability), reported procrastinating less [7].

In the same way, the review of a series of papers on the possible causes of procrastination found that multiple conditions may contribute to the incidence of this behavior. For instance, poor time management, uncertainty about the priority of actions and goals, feelings of discomfort about performing an activity they are unaware of, distortions in the environment such as noise, overload in the tasks or study, or inadequate places to fulfill them, fear and anxiety related to failure, among others $[1,3,6]$.

A study in Peru with university students from the areas of science, humanities, and engineering [8] revealed that the probability that they will initiate, develop, and conclude work without procrastinating, depends on the confidence in their abilities and if the student considers them proportional to the demands established by the task. Another investigation reported a low association between academic procrastination and perfectionism in students of various majors in Iran [9].

In Colombia, a study was conducted with students with different bachelor's degrees, including those in the health area. It was found that adequate self-regulation directly favors their prosperity and their physical and psychosocial health, and indirectly their academic performance. On the contrary, inefficient self-regulation increases their tendency to procrastinate [10]. In a study in Turkey, it was also observed that female students have a more self-regulated academic behavior, probably due to the higher perceived demands, unlike their male peers [11]. However, in the same country, particularly in the medical career, it was found that female students take greater responsibility for their learning than men [12].

Concerning the sex variable, it appears to be significantly associated with procrastination in several papers conducted with university students where it was observed that men tend to procrastinate more than women $[10,13]$. In these and other investigations, age has also been highlighted as another variable significantly associated with procrastination; for instance, the older the age, the less intense this behavior is presented $[10,13,14]$. 
Regarding its negative effects, procrastination can be detrimental to students' health in addition to other factors. Research conducted with students of different bachelor's degrees (including those in the health area) in Argentina showed that those who have higher levels of anxiety when taking a test, and academic procrastination, are more vulnerable to present physical and mental symptoms of anxiety, mood, and personality disorders [15]. On the other hand, in Pakistan, master's degree students showed that the workload and inadequate time management led to procrastinating their tasks, disturbing their academic performance regarding their learning in the classroom, participation in activities, work presentations, and preparing for exams [16].

Finally, after the theoretical review on trends in the study of academic procrastination and its role in university dropout, it was found that the reasons for procrastinating can be grouped into five categories. These are the interest or attraction to the task, the love for work, uncertainty about the assignment, and perfectionism. It was also observed that students with a low tendency to procrastinate are more likely to finish their first-year studies on time, compared to those who procrastinate more. Nevertheless, although procrastination impacts scholarly performance, this effect is mediated by other psychological and academic variables, for instance, the tasks' relevance, course length, its relation to professional life, stress, and self-efficacy.

Within the context of self-regulated learning, it has been proposed that procrastination can be assessed from the moment students enroll in university and working with them can help reduce it to benefit their academic performance and quality of life [17].

There is evidence that shows that university students tend to procrastinate. Thus, the different factors that lead students to procrastinate in their academic activities are currently being studied, along with the distinct ways in which this behavior affects their academic, personal, and family life. Besides the adaptation process that the transition from high school to higher education implies, the high demands of careers such as medicine can lead to greater procrastination in first-year medical students. Knowing to what extent this population tends to postpone their schoolwork and the reasons for doing so will allow designing strategies to reduce procrastination, facilitating their adaptation to the new challenges and their academic performance.

Therefore, the purpose of this study was to investigate procrastination in first-year medical students at a public university in Mexico City, as well as the reasons to which they attribute this behavior.

\section{Method}

\subsection{Design and Participants}

This is a cross-sectional study with a sample of 388 firstyear medical students, members of 16 groups that were randomly selected from a total of 48 . From those, $69.3 \%$ were female, $94.3 \%$ were under 18 years old at the time the research was conducted, and $94.6 \%$ came from public high schools; $59.8 \%$ lived with both parents, $21.6 \%$ with one of them, $7.5 \%$ with another relative, $3.1 \%$ with classmates and $8 \%$ lived alone.

\subsection{Instrument}

Colombian university students were assessed [18] with the Spanish version and adaptation of the Procrastination Assessment Scale-Students (PASS) by Solomon and Rothblum [19]. This instrument consists of two sections. The first section evaluates the level of procrastination in 6 academic domains: 1) writing a term paper, 2) studying for an exam, 3) keeping up with weekly reading assignments, 4) performing administrative tasks, 5) attending meetings, and 6) performing academic tasks in general. Each of these six domains contains three items rated on a 5-point Likert-type scale that measures: a) the frequency of procrastination on academic tasks, b) the extent to which procrastination on the task was causing a problem for students, and c) the extent of students' willingness to decrease their procrastination.

The response options are rated on a Likert-type scale and include $1=$ Never, $2=$ Almost never, $3=$ Sometimes, 4=Nearly always, and 5=Always. In this study sample, the six items that assessed the frequency with which procrastination occurs showed a Cronbach's alpha of .74. The six items regarding the frequency with which postponing the task implies a problem for the student obtained $\alpha=.85$, and the other six items that measure the frequency with which it is desired to reduce procrastination obtained $\alpha=.92$.

The second scale consists of 26 items that explore the reasons that lead students to postpone their school activities, grouped into five subscales proposed by Garzón and Gil [18]: (1) excitement seeking (five items), which explains procrastinating due to rebellion against control, risk-taking and fear of success because it could incite peer rejection; (2) lack of energy and emotional and environmental self-control (ten items), which include the tendency to feel overwhelmed, poorly manage time, peer influence, aversiveness of task, low frustration tolerance, laziness, social dependence and helpseeking; (3) perfectionism (three items), which includes perfectionism and fear of success because this could lead to higher expectations from others about one's future performance; (4) evaluation anxiety (two items), which refers to fear of failure; and (5) low assertiveness and confidence (six items), which involves perceived lack of decisionmaking or social skills to seek information that would help to successfully perform a task. The response options for this scale are also Likert-type ranging from 1= "not at all reflects why I procrastinated" to 5= "definitely reflects why I procrastinated."

In this study sample, the total scale regarding the reasons why the student postpones schoolwork obtained a Cronbach's alpha of .89; while the subscales that compose it obtained the following Cronbach's alphas: excitement seeking, .74; lack of energy and self-control, .76; perfectionism, .81; evaluation anxiety, .69; poor assertiveness and confidence, .79. 


\subsection{Procedure}

After the project was evaluated and approved by the research and ethics committees of the institution where the study was carried out, the instrument was applied through the middle of the school year in the classrooms.

\subsection{Statistical Analysis}

The descriptive analysis of gender, age, school of origin, high school grade point average, mother's schooling, and people with whom the students lived at the time of the application was carried out through frequencies and percentages.

The descriptive analysis of the presence of procrastination in the students, whether it represented a problem for them, the desire to reduce it, including the reasons for procrastinating, was also carried out through frequencies and percentages.

Since the study variables were not normally distributed, the comparative analysis was carried out using the MannWhitney $U$ test for sex, age, and school of origin. The Kruskal-Wallis and Bonferroni tests were used for the high school grade point average, mother's schooling, and people with whom the students lived when applying the instrument. Regarding the results, the means and standard deviations are reported instead of medians with their minimum and maximum values since the first ones sometimes provide more accurate information than the latter.

\section{Results}

Of 400 students who agreed to participate in this research, 388 students were part of the sample since they entirely responded to the instrument applied. Of the latter, $92 \%$ of the high school grade point average was higher than nine. Besides, 39.9\% reported that their mother had a bachelor's or master's degree, $37.9 \%$ high school or a commercial or technical career, and $22.2 \%$ junior high school or less.

As a result of the descriptive analysis, it was found that about a third of the students tended to postpone tasks directly related to study and learning; half of them considered this to be a problem (particularly delaying studying for exams), and more than $60 \%$ expressed a desire to reduce procrastination in these activities. Similarly, it was observed that slightly more than a quarter procrastinated in requesting counseling; about a third considered that this could be a problem, and almost half reported wanting to reduce this tendency. On the other hand, approximately one-fifth of the students procrastinated in carrying out school procedures; slightly less than one-third considered this a problem; almost half wanted to reduce this tendency to postpone them (Table 1).

Table 1. Procrastination of academic activities in students $(n=388)$.

\begin{tabular}{|c|c|c|c|c|}
\hline \multirow{2}{*}{ Activity } & \multirow{2}{*}{ Answer } & \multicolumn{3}{|c|}{ Frequency* } \\
\hline & & 1 & 2 & 3 \\
\hline \multirow{3}{*}{ Writing a term paper. } & It is postponed & 34.5 & 44.3 & 21.1 \\
\hline & Postponing the activity implies a problem. & 46.4 & 29.6 & 24.0 \\
\hline & It is desired to reduce the tendency to postpone it. & 61.6 & 11.3 & 27.1 \\
\hline \multirow{3}{*}{ Studying for exams. } & It is postponed & 29.4 & 35.6 & 35.1 \\
\hline & Postponing the activity implies a problem. & 57.5 & 22.9 & 19.6 \\
\hline & It is desired to reduce the tendency to postpone it. & 64.9 & 6.2 & 28.9 \\
\hline \multirow{3}{*}{ Keeping up with weekly reading assignments. } & It is postponed & 32.7 & 38.1 & 29.1 \\
\hline & Postponing the activity implies a problem. & 47.4 & 27.8 & 24.7 \\
\hline & It is desired to reduce the tendency to postpone it. & 62.9 & 8.5 & 28.6 \\
\hline \multirow{3}{*}{$\begin{array}{l}\text { Performing administrative tasks (filling out forms, } \\
\text { registering for classes, getting an ID card, etc.) }\end{array}$} & It is postponed & 19.3 & 17.3 & 63.4 \\
\hline & Postponing the activity implies a problem. & 30.9 & 21.4 & 47.7 \\
\hline & It is desired to reduce the tendency to postpone it. & 46.9 & 11.9 & 41.2 \\
\hline \multirow{3}{*}{$\begin{array}{l}\text { Attendance tasks (meeting with an advisor, making an } \\
\text { appointment with a professor, etc.). }\end{array}$} & It is postponed & 27.3 & 27.6 & 45.1 \\
\hline & Postponing the activity implies a problem. & 31.4 & 26.8 & 41.8 \\
\hline & It is desired to reduce the tendency to postpone it. & 47.4 & 14.2 & 38.4 \\
\hline \multirow{3}{*}{ School activities in general } & It is postponed & 21.4 & 38.1 & 40.5 \\
\hline & Postponing the activity implies a problem. & 37.6 & 32.2 & 30.2 \\
\hline & It is desired to reduce the tendency to postpone it. & 56.4 & 11.3 & 32.2 \\
\hline
\end{tabular}

* All reported with percentages.

The five response options were collapsed to $1=$ Almost always or always; $2=$ Sometimes; $3=$ Almost never or never.

Another relevant finding was that procrastination was associated, to a greater extent, with a feeling of being overwhelmed by the number of tasks to accomplish, insufficient time to carry them out, laziness to start them, insecurity about how to perform them, and worrying about not being able to achieve their expectations and goals or receiving a poor grade. On the other hand, to a minor extent, procrastination was related to low assertiveness and selfconfidence, peer influence, resistance to what some of the students considered to be tasks on deadlines imposed by others and experiencing excitement when waiting until the last moment to perform a given school activity (Table 2).

When comparing by age, it was observed that younger students procrastinated less than their older peers (Table 3). As for gender, it was found that males tend to postpone more their schoolwork than females as a way of experiencing excitement by rebelling against control and taking risks. On the contrary, females tended to procrastinate more than males 
when feeling overwhelmed by academic work and the lack of time to carry it out (Table 3).

Table 2. Reasons for postponing school activities $(n=388)$.

\begin{tabular}{|c|c|c|c|}
\hline \multirow{2}{*}{ Reasons for procrastinating the activity } & \multicolumn{3}{|c|}{ Reflects the reason* } \\
\hline & 1 & 2 & 3 \\
\hline \multicolumn{4}{|l|}{ Procrastinate searching for excitement. } \\
\hline \multicolumn{4}{|l|}{ Rebellion against control } \\
\hline Resented having to do things assigned by others & 5.2 & 5.9 & 88.9 \\
\hline Resented people setting deadlines for them & 6.2 & 8.5 & 85.3 \\
\hline \multicolumn{4}{|l|}{ Risk-taking } \\
\hline Feeling excitement when doing the task at the last minute & 7.5 & 7.5 & 85.1 \\
\hline Liking the challenge of waiting until the deadline & 6.4 & 7.7 & 85.8 \\
\hline \multicolumn{4}{|l|}{ Fear of success } \\
\hline Being concerned that if they did well, classmates would resent them & 4.9 & 7.0 & 88.1 \\
\hline \multicolumn{4}{|l|}{ Procrastination due to lack of energy and self-control } \\
\hline \multicolumn{4}{|l|}{ Tendency to feel overwhelmed and poorly manage time } \\
\hline Having too many other things to do & 41.8 & 31.2 & 27.1 \\
\hline Feeling overwhelmed by the task & 38.1 & 25.0 & 36.9 \\
\hline \multicolumn{4}{|l|}{ Peer influence } \\
\hline Waited until a classmate gave them some advice on how to perform the task & 13.9 & 24.0 & 62.1 \\
\hline Friends pressured to do other things & 3.9 & 5.4 & 90.7 \\
\hline \multicolumn{4}{|l|}{ Aversiveness of the task and low frustration tolerance } \\
\hline Really disliked the activity & 9.8 & 14.7 & 75.5 \\
\hline Feeling it takes too long to perform the task & 28.1 & 24.0 & 47.9 \\
\hline \multicolumn{4}{|l|}{ Laziness } \\
\hline Did not have enough energy to begin the task & 37.9 & 26.3 & 35.8 \\
\hline Feeling too lazy to start the task & 38.4 & 26.3 & 35.3 \\
\hline \multicolumn{4}{|l|}{ Dependency and help-seeking } \\
\hline Knowing that classmates had not started the paper either & 12.4 & 18.0 & 69.6 \\
\hline Waited to see if the professor would give more information about the paper & 11.6 & 18.6 & 69.8 \\
\hline \multicolumn{4}{|l|}{ Procrastinate due to perfectionism } \\
\hline \multicolumn{4}{|l|}{ Perfectionism } \\
\hline Being concerned about not meeting their expectations & 25.8 & 16.8 & 57.5 \\
\hline Setting high standards for themselves and worrying about not being able to meet those standards & 25.0 & 14.7 & 60.3 \\
\hline \multicolumn{4}{|l|}{ Fear of success } \\
\hline Being concerned that if they got a good grade, people would have higher expectations of them in the future & 13.7 & 11.6 & 74.7 \\
\hline \multicolumn{4}{|l|}{ Procrastination due to evaluation anxiety } \\
\hline \multicolumn{4}{|l|}{ Evaluation anxiety } \\
\hline Being concerned that the professor would not like their work & 16.0 & 15.7 & 68.3 \\
\hline Being worried they would get a bad grade & 29.1 & 15.2 & 55.7 \\
\hline \multicolumn{4}{|l|}{ Procrastinate due to low assertiveness and confidence } \\
\hline \multicolumn{4}{|l|}{ Difficulty making decisions } \\
\hline Having difficulties in knowing how to perform them & 31.4 & 37.1 & 31.4 \\
\hline Could not know what to include and what not to include in their paper & 21.1 & 30.7 & 48.2 \\
\hline \multicolumn{4}{|l|}{ Lack of assertion } \\
\hline There's information they needed to ask the professor, but they felt uncomfortable approaching them & 17.3 & 17.3 & 65.5 \\
\hline Having difficulty requesting information from other people & 7.5 & 19.8 & 72.7 \\
\hline \multicolumn{4}{|l|}{ Lack of self-confidence } \\
\hline Did not think they knew enough to perform the task & 18.3 & 20.9 & 60.8 \\
\hline Did not trust themselves to do a good job & 13.4 & 14.4 & 72.2 \\
\hline
\end{tabular}

* All reported with percentages.

The five response options were collapsed to $1=$ Almost accurately or accurately reflects the reason for postponing the activity; $2=$ To some extent; $3=$ Not almost or not at all.

Finally, when comparing by the school of origin, it was observed that students who attended high school in private schools tend to procrastinate more than those who attended public educational institutions when they had doubts and required assistance. However, they found it hard to approach the teacher or other people to request it (Table 3 ).

\section{Discussion}

This paper evaluated the presence of procrastination in first-year medical students, its relationship with the frequency of academic activities, the tension or discomfort that this can generate, and the reasons why medical students procrastinate. The results help to confirm that the selected instrument was adequate for the established objectives in the research.

It was considered important to include the mother's schooling, because previous research had found a significant relationship with the academic behavior of the students, showing that they had better academic performance when their mother's schooling was higher [20]. However, in this research, a significant association between procrastination 
and the mothers' schooling was not found.

Table 3. Differences in students' procrastination in academic activities ( $n=388)$.

\begin{tabular}{|c|c|c|c|c|c|c|}
\hline & & DE & & DE & $\mathbf{Z}$ & $\mathbf{p}$ \\
\hline Age & \multicolumn{2}{|c|}{$17(\mathrm{n}=366)$} & \multicolumn{2}{|c|}{$\geq 18$ a $20(n=22)$} & & \\
\hline Frequency of procrastination (6 to 30) & 16.87 & 4.35 & 18.86 & 3.87 & -2.42 & .016 \\
\hline Sex & \multicolumn{2}{|c|}{ Women $(n=269)$} & \multicolumn{2}{|c|}{ Men $(\mathrm{n}=119)$} & & \\
\hline Procrastination in search of excitement (5 to 25) & 7.05 & 2.92 & 8.34 & 4.07 & -2.76 & .006 \\
\hline Rebellion against control (2 to 10$)$ & 2.82 & 1.40 & 3.38 & 1.92 & -2.76 & .006 \\
\hline Risk-taking (2 to 10 ) & 2.84 & 1.59 & 3.51 & 2.32 & -2.32 & .020 \\
\hline \multicolumn{7}{|l|}{ Procrastination due to lack of energy and self-control } \\
\hline Tendency to feel overwhelmed and poor time management ( 2 to 10 ) & 6.38 & 2.01 & 5.79 & 2.18 & -2.47 & .013 \\
\hline School of origin & \multicolumn{2}{|c|}{ Public $(\mathrm{n}=367)$} & \multicolumn{2}{|c|}{ Private $(n=21)$} & & \\
\hline Procrastination due to low assertiveness and confidence & & & & & & \\
\hline Low assertiveness ( 2 to 10 ) & 3.97 & 1.95 & 4.95 & 1.94 & -2.33 & .020 \\
\hline
\end{tabular}

The Mann-Whitney U test was used.

(The numbers in parentheses in each variable include the range of minimum and maximum scores that can be obtained on each scale or subscale).

In the descriptive analysis of the percentages, it is evident that procrastinating homework, learning activities, timely seeking counseling, and school paperwork are delayed with relative frequency in college students. This is congruent with what has been mentioned in other research about how procrastination affects classroom learning, participation in academic activities, homework submission, and preparation for exams. Also, the workload of assigned tasks and inadequate time management by students are causes of procrastination, which coincides with what was observed in this study [6, 16-17].

Another remarkable aspect is the expectations of the student, their family, and their surroundings. Studying a career with a high social prestige represents a greater pressure, combined with the possibility of receiving a low grade in students who had an excellent academic trajectory, which may result in a decrease in confidence and security regarding their previous knowledge and the presence of greater delay in starting academic tasks.

The results showed how peers or friends influence as a distracting factor that promotes procrastination, along with the tendency demonstrated by some students to resist meeting deadlines that they consider imposed and rebel against this. These aspects can be understood by the adolescent period in which they are, since being oppositionist and having negative attitudes are characteristic at this stage. Also, as part of this process, some students wait until the last moment to start their responsibilities as a way of experiencing the associated excitement, although to a lesser extent.

Regarding age, previous research indicates that procrastination decreases as people get older, [22] but this sample tended to the opposite, which will be the topic of future research. Many studies have found significant differences concerning procrastination in men and women. Some of them showed that males presented greater procrastination, while others have pointed out women as the gender that more procrastinates. In this investigation, they both procrastinated, but the reasons why they do so are different. Female students procrastinated when they felt overwhelmed by the workload and the short time to complete it, which would be associated with decreased emotional regulation. On the other hand, male students delay their academic activities because they are motivated by a search for excitement and a challenging attitude towards authority $[5,10,11,14,16,21]$.

A notable aspect of the results is that students who came from private schools show great difficulty when asking for help or clarifying their doubts with teachers. They could feel uncomfortable or vulnerable in front of others when seeking support or they could feel different from their peers when not solving their doubts by themselves. These findings are a motivation to continue studying these differences and design new studies to explain these variables.

\section{Conclusions}

The above results help consider procrastination as a behavior that can be detected from school periods before entering university. Therefore, it is important to create induction workshops at the end of high school and the beginning of undergraduate studies, to provide psychoeducation tools that allow students to optimally plan their time and academic tasks, modify their study habits, keep away distracters that interfere with their activities and promote greater self-regulation.

The medical career has been characterized by having a large amount of information that students must assimilate; the number of subjects and the dense content represent a significant burden when they feel that their time is insufficient. This leads them to doubt their permanence in the university and sometimes causes them to drop out.

From the data provided in the literature, it is known that when the student has information about the career he or she is enrolling for and feels more satisfied and capable of studying it, then they will be more committed to their academic work. Hence, it is necessary to influence from high school education so that the student not only makes the best decision based on their interests and vocational aptitudes but also making sure they have the necessary tools to assimilate the knowledge and organize their learning strategies.

This study invites to deliberate on the possible adaptations in the educational system that can promote optimal learning 
and encourage healthy academic behavior. Based on accurate data, it is possible to develop proposals that impact bad practices, such as procrastination, and to know the motivation for delaying school activities and the influences that postpone these responsibilities.

These results open the possibility of investigating other variables associated with procrastination; for instance, the expectations that parents may have towards the university student, whether the student has parental support, whether there is a maternal model that guides students towards academic achievement, the difference in emotional regulation between men and women, cultural and social influences that may contribute to greater academic pressure, as well as the phase of personal development and the influence of peers in men and women.

Conducting this research in different years of the medical career and observing the behavior of procrastination over time, as well as studying procrastination in other careers and comparing the results is a topic of interest.

\section{Conflict of Interest}

All the authors do not have any possible conflicts of interest.

\section{References}

[1] Angarita Becerra, L. D. (2012). Approach to an updated concept of procrastination. Ibero-American Journal of Psychology: Science and Technology, 5 (2), 85-94.

[2] Atalaya Laureano, C. and García Ampudia, L. (2019). Procrastination: Theoretical Review. Journal of Research in Psychology, 22 (2), 363-378.

[3] Quant, D. M. and Sánchez, A. (2012). Procrastination, Academic Procrastination: Concept and Implications. Theoretical and Practical Clinical Psychological Vanguard Journal, 3 (1). 45-59.

[4] Marquina Luján, R. J., Gómez Vargas, L., Salas Herrera, C., Santibañez Gihua, S. and Rumiche Prieto, R. (2016). Procrastination in college students of metropolitan Lima. Peruvian Journal of Obstetrics and Nursing, 12 (1). 1-16.

[5] Carranza, R. and Ramírez, A. (2013). Procrastination and demographic characteristics associated with college students. University Notes Research Journal, III (2), 95-108.

[6] Cao, L. (2012). Differences in procrastination and motivation between undergraduate and graduate students. Journal of the Scholarship of Teaching and Learning, 12 (2), 39-64.

[7] Clariana, M., Cladellas, R., Badía, M. M. and Gotzens, C. (2011). The influence of gender on personality variables conditioning learning: Emotional intelligence and academic procrastination. Inter-University Electronic Journal of Teacher Training, 14 (3), 87-96.
[8] Alegre, A. A. (2013). Self-efficacy and academic procrastination of university students in Metropolitan Lima. Purposes and Representations, 1 (2), 57-82.

[9] Jadidi, F., Mohammadkhani, S. and Tajrishi, K. Z. (2011). Perfectionism and academic procrastination. Procedia Social and Behavioral Science, 30, 534-537.

[10] Garzón Umerenkova, A., de la Fuente, J., Amate, J., Paoloni, P. V., Fadda, S. and Pérez, J. F. (2018). A linear empirical model of self-regulation on flourishing, health, procrastination, and achievement, among university students. Frontiers in Psychology, 9, 536.

[11] Özer, B. U., Demir, A. and Ferrari, J. R. (2009). Exploring academic procrastination among Turkish students: possible gender differences in prevalence and reasons. Journal of Social Psychology, 149 (2), 241-257.

[12] Demirören, M., Turan, S. and Öztuna, D. (2016). Medical students' self-efficacy in problem-based learning and its relationship with self-regulated learning. Medical Education Online, 21, 30049.

[13] Mejía, C. R., Ruiz, F. N., Benites, D. and Pereda, W. (2018). Academic factors associated with procrastination. Cuban Journal of General Comprehensive Medicine, 34 (3). 61-70.

[14] Rodríguez, A. and Clariana, M. (2017). Procrastination in University Students: The Relationship to Age and Academic Year. Colombian Journal of Psychology, 26 (1), 45-60.

[15] Furlan, L. A., Ferrero, M. J. and Gallart, G. (2014). Test anxiety, procrastination, and mental symptoms in university students. Argentine Journal of Behavioral Sciences, 6 (3), 31-39.

[16] Hussain, I. and Sultan, S. (2010). Analysis of procrastination among university students. Procedia Social and Behavioral Sciences, 5, 1897-1904.

[17] Garzón Umerenkova, A. and Gil Flores, J. (2017). The role of academic procrastination as a factor of university abandonment. Complutense Journal of Education, 28 (1), 307-324.

[18] Garzón Umerenkova, A. and Gil Flores, J. (2017). Psychometric Properties of the Spanish Version of the Test Procrastination Assessment Scale-Students (PASS). IberoAmerican Journal of Psychological Diagnosis and Evaluation - e Avaliação Psicológica. RIDEP, 43 (1), 149-163.

[19] Solomon, L. J. and Rothblum, E. D. (1984). Academic procrastination: Frequency and cognitive-behavioral correlates. Journal of Counseling Psychology, 81 (4), 503-509.

[20] Rodríguez, D. and Guzmán, R. (2019) Academic performance and socio-familial risk factors. Educational profiles. Vol XLI, num $164,118-134$.

[21] Steel P. and Ferrari J. (2013) Sex, education, and procrastination: An epidemiological study of procrastinators' characteristics from a global sample. European Journal of Personality. 27: 51-58.

[22] Diaz-Morales J. (2019) Procrastination: A Review of Scales and Correlates. Ibero-American Journal of Diagnosis and Evaluation. No. 51, Vol. 2 43-60. 